\section{Pecan Nut Suture Splits Are Positively Related to Kernel Moisture Concentration and Solar Radiant Exposure}

\author{
Michael W. Smith ${ }^{1,3,5}$ and William D. Goff ${ }^{2,4}$
}

AdDitional IndeX wORDs. Carya illinoinensis, crack, sunlight

Summary. Pecan (Carya illinoinensis) nuts with cracked shells reduce market grade and are usually removed during pecan cleaning. One type of crack is the shell suture that splits on certain cultivars with thin shells and high kernel percentages. 'Schley' nuts with diverse kernel moisture concentrations were dislodged from trees on cloudy and sunny days and exposed to ambient environmental conditions for 1 day on the ground. Samples were collected immediately after dislodging and after 1 day's exposure, sealed in a plastic bag that was placed in a cooler, and then transported to the laboratory where they were assessed for kernel moisture and split sutures. The number of nuts with split sutures was unaffected by kernel moisture percentage or sunlight exposure when samples were collected immediately after dislodging. However, after 1 day, nuts with high kernel moisture percentages with high solar radiant exposure (sunny day) had substantially more nuts with suture splits than those with low solar radiant exposure (cloudy day). At the lowest kernel moisture percentages, the number of nuts with split sutures was insensitive to solar radiant exposure. During the first harvest, 'Schley' trees should be shaken to dislodge nuts on cloudy days and harvested before exposure to bright sunshine to minimize suture split. This probably extends to other cultivars with a history of suture split. An alternative to shaking on cloudy days, though not tested, might be to shake trees in the evening and harvest the next morning before exposure to high light conditions. Later, during the harvest season when kernel moisture was lower, sunlight exposure has little, if any, effect on suture splits.

$\mathrm{P}$ ecans with cracked shells (ovary wall) are typically removed during cleaning in preparation for marketing. The value of cracked nuts is substantially less than those with intact shells. If cracked nuts are not removed during cleaning the grade is reduced, consequently the pecans have less value.

Shells may be cracked by machinery during harvest and postharvest handling. These cracks occur anywhere on the shell and are often irregular in shape. Another crack

Approved for publication by the directors of the Oklahoma Agricultural Experiment Station.

Funding for this research is provided by the Oklahoma Agricultural Experiment Station and Friendship Pecan Farm, Baconton, GA.

The authors gratefully acknowledge the assistance of Samuel L. Wright, GA Automated Environmental Monitoring Network, Griffin, GA, for supplying daily total solar radiant exposure data.

${ }^{1}$ Department of Horticulture and Landscape Architecture, Oklahoma State University, Stillwater, OK 74078

${ }^{2}$ Department of Horticulture, Auburn University, Auburn, AL 36849

${ }^{3}$ Regents Professor

${ }^{4}$ Nunn Bond Professor and Extension Horticulturist Emeritus

${ }^{5}$ Corresponding author. E-mail: mike.smith@okstate. edu. frequently observed on certain cultivars is a split along the shell suture. Cultivars with a tendency to have suture splits are those with thin shells and high kernel percentages, such as Schley (Eastern Schley), Wichita, Mohawk, and Oconee. Reduced crop value from split sutures can be considerable. Additionally, cracking exposes the kernels to entry by rotting fungi and bacteria, and to ants, so cracked nuts deteriorate more rapidly.

Many producers harvest highvalue nuts twice; the first time shortly after shuck (involucre) split (i.e., when the nut is fully ripe) while trees are foliated and shucks are green, followed by a second harvest after a killing frost. Early season, top-quality pecans are in demand for direct market retailers that sell to customers before the Thanksgiving and Christmas holidays, and for export to China to arrive in time for the Chinese New
Year. These early season nuts typically bring substantially higher prices than those harvested and marketed later in the season. A common practice for the first harvest in locations without notable depredation when pecans are on the ground is to dislodge the nuts from the tree and leave them on the ground $\mathrm{l} \mathrm{d}$ or more to dry. Otherwise, harvest procedures are completed the same day that the nuts are shaken from the tree. Observations suggest that nuts with split sutures are more plentiful during the first harvest than during later harvests.

No literature that addresses the cause or incidence of pecan split sutures was found. Therefore, a study was designed to elucidate the losses caused by split sutures and possible factors associated with suture split. We hypothesized that suture splits of thin-shelled cultivars is associated with a high kernel moisture concentration at the time of harvest and is exacerbated by rapid drying associated with abundant sunlight exposure during harvest. To test this hypothesis, we harvested trees in cloudy and sunny conditions during the first and second harvests and evaluated the nuts for suture split.

\section{Materials and methods}

The study was conducted at Friendship Pecan Farm located $\approx 8$ miles north of Baconton, GA (lat. $31^{\circ} 30^{\prime} \mathrm{N}$, long. $84^{\circ} 05^{\prime} \mathrm{W}$ ). Thirty uniform size $\approx 80$-year-old 'Schley' trees with crop loads ranging from $40 \%$ to $70 \%$ fruit bearing shoots were selected for the study. Kernel percentages of harvested nuts averaged $54.7 \%$ across all trees. Trees were growing on a Tifton sandy loam (fine-loamy, kaolinitic, thermic Plinthic Kandiudults).

Twenty randomly selected trees, from the 30 trees designated for the study, were harvested between 22 Oct. and 4 Nov. 2013 while trees were fully foliated and shucks were green but sufficiently open for the first harvest. Nuts from five trees were shaken to the ground on each of the following dates 22 Oct. (cloudy), 23

\begin{tabular}{llll}
\hline $\begin{array}{l}\text { Units } \\
\begin{array}{l}\text { To convert U.S. to SI, } \\
\text { multiply by }\end{array}\end{array}$ & U.S. unit & SI unit & $\begin{array}{l}\text { To convert SI to U.S., } \\
\text { multiply by }\end{array}$ \\
\hline 38.7501 & $\mathrm{~kW}-\mathrm{h} / \mathrm{ft}^{2}$ & $\mathrm{MJ} \cdot \mathrm{m}^{-2}$ & 0.0258 \\
0.4536 & $\mathrm{lb}$ & $\mathrm{kg}$ & 2.2046 \\
1.6093 & $\mathrm{mile}(\mathrm{s})$ & $\mathrm{km}$ & 0.6214 \\
$\left({ }^{\circ} \mathrm{F}-32\right) \div 1.8$ & ${ }^{\circ} \mathrm{F}$ & ${ }^{\circ} \mathrm{C}$ & $\left({ }^{\circ} \mathrm{C} \times 1.8\right)+32$
\end{tabular}


Oct. (sunny), 31 Oct. (sunny), and 4 Nov. (sunny). The remaining ten trees were harvested on 14 (cloudy) and 18 (sunny) Dec. 2013 when the trees were defoliated and shucks were dead and dried with nuts retained in the shucks. Harvesting consisted of dislodging the nuts with a mechanical shaker at $\approx 9: 00$ to $10: 00 \mathrm{AM}$, and then allowing them to remain on the ground until the following morning. About $4 \mathrm{lb}$ of nuts $(\approx 210$ nuts) were randomly harvested by hand from each tree when nuts were dislodged and again immediately before machine harvest the following morning. Nut samples were immediately sealed in a plastic bag, placed in a cooler, and transported to the laboratory for determination of kernel moisture and the number of nuts with split sutures.

Kernel moisture was determined with a seed moisture meter (SB 900; Steinlite, Atchison, KS). Temperature and humidity at the time nuts were shaken from the tree and at solar noon were recorded. Total nuts per sample and those with split sutures were determined by inspection and the percentage of nuts with suture splits calculated. Daily total solar radiant exposure (DTSRE) during the day nuts laid on the ground was obtained from the Georgia Automated Environmental Monitoring Network; Griffin, GA, for the Albany, GA station located $\approx 6$ miles northwest of the orchard.

Data were analyzed using regression analysis. Independent variables were kernel moisture percentage, temperature, and humidity at the time nuts were dislodged from the tree, temperature and humidity at solar noon, and DTSRE for the day they laid on the ground. Data were analyzed using least square techniques (Draper and Smith, 1966). The linear, quadratic, and cubic components for the main effects of independent variables and their interaction were evaluated using type 1 and 3 sum of squares and appropriate components retained in the model.

\section{Results and discussion}

Kernel moisture for nuts during the first harvest ranged from $6.8 \%$ to $19.5 \%$ and those in the second harvest had $4.8 \%$ to $6.5 \%$ moisture. Temperature when trees were shaken ranged from 8 to $22^{\circ} \mathrm{C}$ and at solar noon 19 to $26{ }^{\circ} \mathrm{C}$. Humidity was $50 \%$ to $79 \%$ and $38 \%$ to $72 \%$ when nuts were dislodged and at solar noon, respectively. DTSRE for sunny days ranged from 11.28 to $17.27 \mathrm{MJ} \cdot \mathrm{m}^{-2}$ and on cloudy days from 3.01 to $3.5 \mathrm{MJ} \cdot \mathrm{m}^{-2}$. The equation listed in Fig. 1 allows the reader to predict the percentage of split sutures for any DTSRE and kernel moisture percentage within the range of DTSRE and kernel moisture in this study. We choose $16 \mathrm{MJ} \cdot \mathrm{m}^{-2}$ as representative of a sunny day with few clouds and $3 \mathrm{MJ} \cdot \mathrm{m}^{-2}$ as representative of overcast conditions in Georgia to illustrate the effects of sunlight exposure and kernel moisture on split sutures. Since DTSRE represents the entire day's exposure to radiant energy, days with passing clouds, although sunny, have less DTSRE than days with few or no clouds (i.e., 11 vs. $17 \mathrm{MJ} \cdot \mathrm{m}^{-2}$ ).

None of the independent variables tested were related to the amount of nuts with split sutures immediately after dislodging from the tree. Nuts with split sutures sampled immediately after dislodging averaged $1.5 \%$.

Kernel moisture, DTSRE, and their interaction made significant contributions to the model estimating nuts with split sutures $1 \mathrm{~d}$ after exposure on the ground to prevailing ambient environmental conditions (Fig. 1). Neither temperature nor humidity made significant model contributions when DTSRE was in the model. Results indicated that during the first harvest when kernel moisture was highest, pecans were extremely sensitive to DTSRE. Nuts harvested in late October with $10.5 \%$ to $19.5 \%$ moisture and on sunny days (16 MJ $\cdot \mathrm{m}^{-2}$ DTSRE) had $4 \%$ to $11 \%$ of the nuts with split sutures. Nuts harvested in November had 6.3\% to 9.9\% moisture and when dislodged from the tree on sunny days had $1 \%$ to $4 \%$ split sutures ranging. Kernel moisture of December harvested nuts were lower than those harvested in $\mathrm{No}^{-}$ vember and dislodging nuts on sunny days resulted in $<1 \%$ of the nuts with split sutures.

Harvesting early season nuts on cloudy days dramatically reduced the percentage of nuts with split sutures (Fig. 1). For instance, nuts with 19.5\% kernel moisture shaken from the tree on sunny days $\left(16 \mathrm{MJ} \cdot \mathrm{m}^{-2}\right.$ DTSRE) had $11 \%$ of the nuts with split sutures, but when dislodged from the tree on cloudy days $\left(3 \mathrm{MJ} \cdot \mathrm{m}^{-2}\right.$ DTSRE) only $2 \%$ of the nuts had split sutures. Kernel moisture concentration when nuts were exposed to a cloudy day had minimal effects on the percentage of nuts split, but on sunny days dramatically affected the percentage of nuts with split sutures.

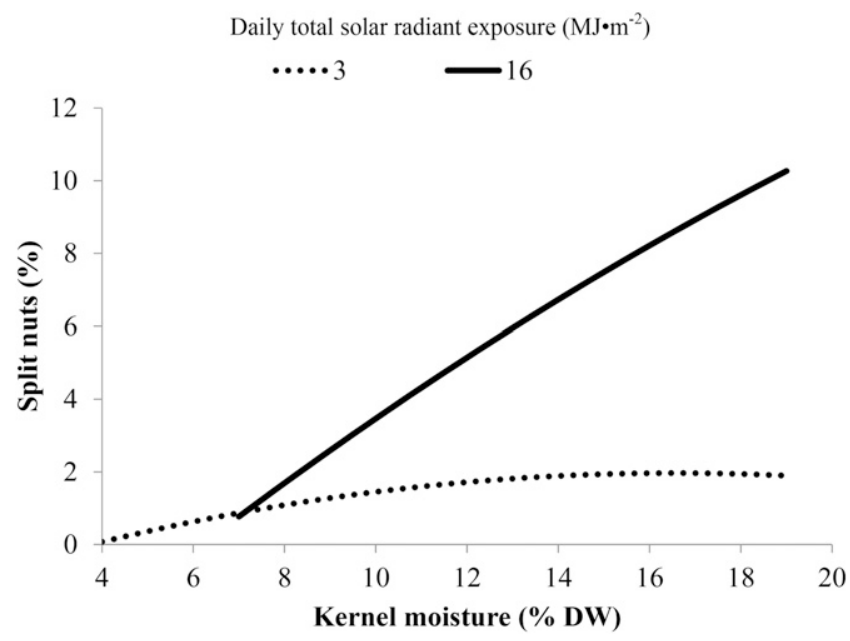

Fig. 1. The relationship of pecan kernel moisture concentration when nuts are dislodged from the tree and daily total solar radiant exposure on the day nuts are dislodged with the percentage of nuts with split sutures sampled after ambient environmental exposure $1 \mathrm{~d}$ on the ground. Typical sunny and cloudy days chosen to illustrate the interaction with kernel moisture concentration were 16 and $3 \mathrm{MJ} \cdot \mathrm{m}^{-2}$, respectively. $\hat{\mathrm{Y}}=-4.08+0.2344 \mathrm{x}-0.01199 \mathrm{x}^{2}+1.164253 \mathrm{z}-$ $0.081687 \mathrm{z}^{2}+0.054299 \mathrm{xz}, \mathrm{R}^{2}=0.65, P<0.0001$; where $\hat{\mathrm{Y}}$ is the estimated percentage of nuts with split sutures, $x$ is the kernel moisture percentage when dislodged from the tree, and $\mathrm{z}$ is the daily total solar radiant exposure in megajoules per square meter; DW = dry weight, $1 \mathrm{MJ} \cdot \mathrm{m}^{-2}=0.0258 \mathrm{~kW}-\mathrm{h} / \mathrm{ft}^{2}$. 


\section{Preliminary and Regional Reports}

Data from those nuts collected immediately following dislodging from the tree and nuts that remained on the ground for $1 \mathrm{~d}$ during cloudy weather indicated that $\approx 1.5 \%$ to $2 \%$ of the 'Schley' nuts had split sutures before being dislodged or when they struck limbs or the ground while falling from the tree. Early season harvest can minimize nut loss by harvesting only on cloudy days; otherwise, losses over normal suture split were $\geq 9 \%$ of the crop when harvested on sunny days. As kernel moisture concentration decreased, the importance of harvesting on cloudy days diminished, and suture split was similar on sunny and cloudy days when kernel moisture was $\approx 6 \%$ or less.

\section{Literature cited}

Draper, N.R. and H. Smith. 1966. Applied regression analysis. Wiley, New York, NY. 